\title{
The effects of goal-directed fluid therapy based on dynamic parameters on post-surgical outcome: a meta-analysis of randomized controlled trials
}

\author{
Jan Benes ${ }^{1 *}$, Mariateresa Giglio², Nicola Brienza ${ }^{2}$ and Frederic Michard ${ }^{3}$
}

\begin{abstract}
Introduction: Dynamic predictors of fluid responsiveness, namely systolic pressure variation, pulse pressure variation, stroke volume variation and pleth variability index have been shown to be useful to identify in advance patients who will respond to a fluid load by a significant increase in stroke volume and cardiac output. As a result, they are increasingly used to guide fluid therapy. Several randomized controlled trials have tested the ability of goal-directed fluid therapy (GDFT) based on dynamic parameters (GDFTdyn) to improve post-surgical outcome. These studies have yielded conflicting results. Therefore, we performed this meta-analysis to investigate whether the use of GDFTdyn is associated with a decrease in post-surgical morbidity.

Methods: A systematic literature review, using MEDLINE, EMBASE, and The Cochrane Library databases through September 2013 was conducted. Data synthesis was obtained by using odds ratio (OR) and weighted mean difference (WMD) with 95\% confidence interval (Cl) by random-effects model.

Results: In total, 14 studies met the inclusion criteria (961 participants). Post-operative morbidity was reduced by GDFTdyn (OR 0.51; Cl 0.34 to $0.75 ; P<0.001$ ). This effect was related to a significant reduction in infectious (OR 0.45; $\mathrm{Cl} 0.27$ to $0.74 ; P=0.002$ ), cardiovascular (OR 0.55; Cl 0.36 to $0.82 ; P=0.004$ ) and abdominal (OR $0.56 ; \mathrm{Cl} 0.37$ to $0.86 ; P=0.008)$ complications. It was associated with a significant decrease in ICU length of stay (WMD -0.75 days; $\mathrm{Cl}-1.37$ to $-0.12 ; P=0.02)$.

Conclusions: In surgical patients, we found that GDFTdyn decreased post-surgical morbidity and ICU length of stay. Because of the heterogeneity of studies analyzed, large prospective clinical trials would be useful to confirm our findings.
\end{abstract}

\section{Introduction}

It has been known for a while that mechanical ventilation may induce cyclic changes in left ventricular stroke volume and arterial pressure [1]. Many experimental and clinical studies have demonstrated that the magnitude of the arterial pressure waveform variation is highly dependent on blood volume [2]. The idea to use the systolic pressure variation (SPV) or the pulse pressure variation (PPV) not only to track changes in blood volume, but also to predict fluid responsiveness (defined as the hemodynamic response to a fluid load), emerged 15 years ago [3-5]. Tavernier et al.

\footnotetext{
* Correspondence: benesj@fnplzen.cz

'Department of Anaesthesia and Intensive Care Medicine, The Faculty of Medicine and University hospital in Plzen, Charles University Prague, Alej Svobody 80, 30640 PIzen, Czech Republic

Full list of author information is available at the end of the article
}

[5] demonstrated that SPV is a better predictor of fluid responsiveness than left ventricular end-diastolic area, an echocardiographic marker of cardiac preload. Michard et al. [3] demonstrated that PPV is an accurate predictor of fluid responsiveness, dramatically better than cardiac filling pressures, and slightly but significantly better than SPV. Since then, many clinical studies have confirmed the value of SPV and PPV to predict fluid responsiveness [2]. Others dynamic parameters, mainly the stroke volume variation (SVV) measured by pulse contour methods [6] and the pleth variability index (PVI) derived from pulse oximetry [7], have also been proposed and used with success to predict fluid responsiveness. Today, most hemodynamic monitors calculate automatically and display these dynamic parameters. According to published peer-reviewed 
surveys, their clinical use to guide fluid therapy increased from $1 \%$ in 1998 [8] to $45 \%$ in 2012 [9].

If the ability of dynamic parameters to predict fluid responsiveness is now hardly disputable (pending the limitations to their use being respected), whether their use is associated with improved quality of care and outcome remains an open question. In 2007, Lopes et al. [10] were the first to demonstrate that intra-operative goaldirected fluid therapy (GDFT) based on PPV monitoring is able to decrease post-operative complications and hospital length of stay in patients undergoing major abdominal surgery. However, the following year, Buettner et al. [11] failed to reproduce these results, although their study design was very similar. Since then, several other randomized controlled trials (RCTs) have been performed where fluid therapy was driven by the use of dynamic parameters. These studies have yielded conflicting results. Therefore, we performed the present meta-analysis in order to clarify if GDFT based on dynamic parameters (GDFTdyn) may decrease post-surgical morbidity when compared to standard fluid management.

\section{Material and methods Eligibility criteria}

The study was performed in adherence to the PRISMA statement (for the full PRISMA statement checklist see the supplemental digital content in Additional file 1) [12], no ethics board approval was deemed necessary for a meta-analysis of previously published studies. Eligible studies were searched according to the following criteria:

\section{Type of participants}

Adult (age 18 years or over) patients undergoing surgery were considered. Studies involving mixed population of critically ill or non-surgical patients were excluded.

\section{Type of intervention}

Intervention was defined as GDFT based on dynamic parameters (GDFTdyn).

\section{Type of comparison}

RCTs comparing the effects of GDFTdyn and standard fluid management were considered.

\section{Type of outcome measures}

The primary outcome measure was post-surgical morbidity. Morbidity was defined as the proportion of patients with one or more post-surgical complication. The specific post-surgical infectious, cardiac, respiratory, renal and abdominal complications, as well as ICU and hospital length of stay were assessed as secondary outcome variables. Abdominal complications included both gastrointestinal and liver complications.

\section{Types of studies}

No language, publication date, or publication status restrictions were imposed.

\section{Information sources}

Different search strategies were performed to retrieve relevant studies by using MEDLINE, The Cochrane Library and EMBASE databases (last update September 2013). No date restriction was applied for MEDLINE and The Cochrane Library databases, while the search was limited to 2006 to 2013 for EMBASE database [13]. Additional trials were searched in The Cochrane Library and in the DARE databases and the reference lists of previously published reviews and retrieved articles.

\section{Search}

We used the following search terms to search all trials: randomized controlled trial, controlled clinical trial, goal directed, goal oriented, goal target, cardiac output, cardiac index, oxygen delivery, oxygen consumption, cardiac volume, stroke volume, fluid therapy, fluid loading, fluid administration, optimization, pulse pressure variation, pleth variability index, stroke volume variation, systolic pressure variation. The search strategies used for MEDLINE, The Cochrane Library and EMBASE databases are shown in the supplemental digital content in Additional file 2.

\section{Study selection}

Two investigators (MTG, NB) examined at first each title and abstract to identify potentially relevant articles. The eligibility of the retrieved full-text articles was independently determined by three investigators (JB, NB, FM). Only trials where dynamic predictors were used to titrate fluid administration were considered for analysis. All identified articles were in English so no text translations were necessary.

\section{Data collection process}

Data were independently collected by two investigators (JB, MTG) with any discrepancy resolved by re-inspection of the original article. To avoid transcription errors, the data were input into statistical software and rechecked by a third investigator $(\mathrm{NB})$.

\section{Data items}

Data abstraction included number of patients, type of surgery, dynamic parameter used to guide fluid therapy, technology used to measure dynamic parameters, type of fluid administered, as well as the outcome variables described above. 


\section{Risk of bias in individual studies}

The Scottish Intercollegiate Guidelines Network (SIGN) checklist for RCTs was used to evaluate the methodological quality of RCTs [14]. The SIGN checklist was independently filled by two investigators (MTG, JB) and whenever different, the study was further assessed in order to reach consensus. A double plus $(++)$ denotes studies very unlikely to have bias, a single plus $(+)$ denotes studies where bias is unlikely, and a minus (-) studies with high risk of bias. A double plus was assigned to studies that adequately described all the criteria of randomization, concealment, blinding, intention-to-treat analysis, and predefined outcomes, whereas a single plus was given to studies meeting only four out of the five criteria. The adequacy of these five criteria is strongly associated with bias reduction $[15,16]$. With regard to blinding, studies in which the outcome variables were collected by investigators not aware of the intra-operative fluid strategy were considered adequately masked [17].

\section{Summary measures and planned method of analysis}

Meta-analytic techniques (analysis software RevMan, version 5.2 Cochrane Collaboration, Oxford, England, UK) were used to combine studies using odds ratios (OR) and 95\% confidence intervals (CI) for dichotomous variables, and weighted mean difference (WMD) and 95\% CI for continuous variables. A statistical difference between groups was considered to occur if the pooled 95\% CI did not include one for the OR. An OR less than one favored GDFTdyn when compared with standard fluid treatment. Two-sided $P$ values were calculated. A randomeffects model was chosen for all analyses. Statistical heterogeneity and inconsistency were assessed by using the $\mathrm{Q}$ and $\mathrm{I}^{2}$ tests, respectively $[18,19]$. When the $P$ value of the $\mathrm{Q}$-test was $<0.10$ and/or the $\mathrm{I}^{2}$ was $>40 \%$ heterogeneity and inconsistency were considered significant [20].

\section{Results}

\section{Study selection}

The search strategies identified 3,297 (MEDLINE), 9,852 (Cochrane Library) and 2,205 (EMBASE) articles. Thirteen articles were identified through other sources (reference lists). After initial screening and subsequent selection, a pool of 105 potentially relevant RCTs was identified. The subsequent eligibility process (Figure 1) excluded 91 articles. Among these, in six trials dynamic predictors of fluid responsiveness were used for GDFT in surgical patients, but the following reasons precluded their inclusion: studies comparing two GDFTdyn approaches [21-24], or studies comparing GDFTdyn to GDFT based on flow parameters [25], or studies using GDFTdyn but without any comparison group [26]. Two meeting abstracts fulfilled eligibility criteria [27,28], but were excluded because of not providing enough information in regard of methodology and patients outcomes and never making it to full publication. Overall, 14 articles [10,11,29-40] with a total sample of 961 patients, were considered for the analysis.

\section{Study characteristics}

All selected articles were RCTs evaluating the effects of GDFTdyn on post-operative complications or length of stay. All studies were published between 2007 and 2013. All RCTs but two [30,33] were single-center trials. Eleven studies included major abdominal procedures, two cardiac surgeries and one a thoracic procedure. Eight studies were performed in Europe, three in China and one in each of the following countries: the United States, India and Brazil (Table 1).

Missing or uncertain information was gathered by direct communication with the authors (see Acknowledgements section). Characteristics concerning the 14 RCTs analyzed are summarized in Table 1. Dynamic parameters used to guide fluid therapy were SVV in eight studies, PPV in four studies, SPV in one study and PVI in one study. SVV was measured by the FloTrac/Vigileo system (Edwards Lifesciences, Irvine, CA, USA) in seven studies and by the PiCCO system (Pulsion Medical Systems SE, Munich, Germany) in one study, PPV was measured by the bedside monitor in three studies and the ProAQT/Pulsioflex system (Pulsion Medical Systems SE) in one study, SPV was measured by the bedside monitor and PVI by the Radical 7 pulse oximeter (Masimo Corp, Irvine, CA, USA). The methodological evaluation, according to the SIGN score, showed that 10 out of 14 studies were considered as having low risk of bias (either ' ++ ' or ' + ' in Table 2).

\section{Outcome measures}

The overall morbidity rate was obtained from 10 studies [10,30,32,33,35-40] and a significant reduction was observed in favor of GDFTdyn (OR 0.51; CI 0.34 to 0.75 ; $P<0.001 ; \mathrm{I}^{2}=28 \%$ ) (Figure 2). A significant reduction in infectious (OR 0.45 ; CI 0.27 to $0.74 ; P=0.002 ; \mathrm{I}^{2}=$ $30 \%$ ), cardiovascular (OR 0.55 ; CI 0.36 to $0.82 ; P=0.004$; $\mathrm{I}^{2}=0 \%$ ) and abdominal complications (OR 0.56; CI 0.37 to $0.86 ; P=0.008 ; \mathrm{I}^{2}=3 \%$ ) was observed in favor of GDFTdyn (Figures 3, 4 and 5). A non-significant trend towards a reduction in respiratory complications was observed (0.60; CI 0.33 to $\left.1.09 ; P=0.09 ; I^{2}=0 \%\right)$. Renal complications were not significantly reduced by GDFTdyn (0.57; CI 0.24 to $1.35 ; P=0.20 ; \mathrm{I}^{2}=40 \%$ ).

A significant reduction in ICU length of stay was also observed (WMD -0.75 days; $\mathrm{CI}-1.37$ to $-0.12 ; P=0.02$; $\mathrm{I}^{2}=52 \%$ ) (Figure 6 ), whereas hospital length of stay did not significantly decrease (WMD -1.33 days; CI -2.90 to $0.23 ; P=0.10 ; \mathrm{I}^{2}=78 \%$ ). 


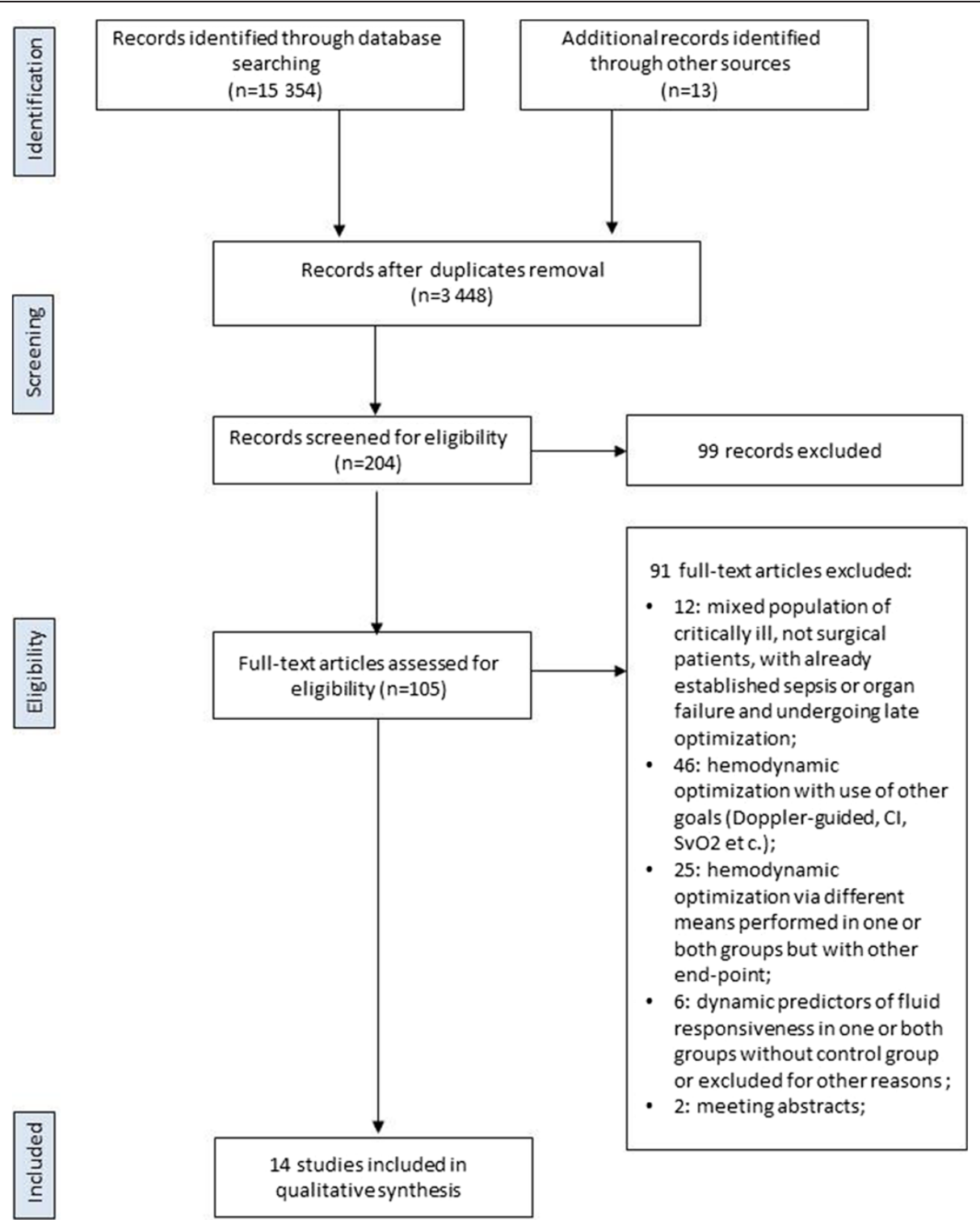

Figure 1 Flow diagram illustrating search strategy. Cl: cardiac index; $\mathrm{SvO}_{2}$ : central venous saturation; $\mathrm{SW}$ : stroke volume variation.

\section{Discussion}

Our meta-analysis shows that GDFTdyn decreases postsurgical morbidity, the rate of infectious, cardiac and abdominal complications, as well as ICU length of stay.

Many post-surgical complications are related, at least in part, to insufficient or excessive fluid administration during the peri-operative period [41]. A U-shaped relationship is classically described between the amount of fluid administered peri-operatively and the morbidity rate [41]. It has been suggested that giving fluid until patients' heart has reached the plateau of the Frank-Starling relationship may be the most efficient way to prevent both hypovolemia and fluid overload. In clinical practice, this approach consists of giving fluid until flow parameters (stroke volume or cardiac output) reach a plateau value (to prevent hypovolemia), then to stop giving any additional fluid volume (to prevent fluid overload).

Dynamic predictors of fluid responsiveness are not markers of blood volume, nor markers of cardiac preload, but markers of the position on the Frank-Starling curve [2]. In this regard, they have been proposed to identify when the plateau of the Frank-Starling relationship is reached without the need to give fluid and to monitor flow parameters [42]. Several randomized controlled trials and meta-analyses have demonstrated the superiority of GDFT based on flow parameters over standard fluid management to decrease renal, gastrointestinal, respiratory and infectious complications, as well as the overall morbidity rate [43-50]. From a physiological standpoint, maximizing stroke volume or minimizing dynamic parameters with 
Table 1 Characteristics of included GDFTdyn studies

\begin{tabular}{|c|c|c|c|c|c|c|c|c|c|}
\hline Study & Type of surgery & Risk & $\begin{array}{l}\text { Number of } \\
\text { participants }\end{array}$ & Timing & $\begin{array}{l}\text { GDFTdyn } \\
\text { end point }\end{array}$ & Other optimization goals & $\begin{array}{l}\text { Type of } \\
\text { intervention }\end{array}$ & $\begin{array}{l}\text { Mortality } \\
\text { reported }\end{array}$ & Morbidity reported \\
\hline $\begin{array}{l}\text { Benes, } 2010 \\
\text { [38] Europe }\end{array}$ & Major abdominal & High & $120(60 / 60)$ & Intra & SW $<10 \%$ & $\begin{array}{l}\mathrm{Cl}>2.5 \mathrm{l} / \mathrm{min} / \mathrm{m}^{2}, \mathrm{MAP}>65 \mathrm{mmHg} \\
\mathrm{CVP}<15 \mathrm{mmHg}\end{array}$ & Fluids, inotropes & Y & $\begin{array}{l}\mathrm{CV}, \mathrm{Gl} \text {, infectious, } \\
\text { renal, respiratory }\end{array}$ \\
\hline $\begin{array}{l}\text { Buettner, } 2008 \\
\text { [11] Europe }\end{array}$ & Major abdominal & Moderate & $80(40 / 40)$ & Intra & SPV $<10 \%$ & N/A & Fluids & Y & - \\
\hline $\begin{array}{l}\text { Forget, } 2010 \\
\text { [37] Europe }\end{array}$ & Abdominal & Moderate & $82(41 / 41)$ & Intra & $\mathrm{PVI}<10 \%$ & MAP $>65 \mathrm{mmHg}$ & Fluids & Y & CV, Gl, infectious, renal \\
\hline $\begin{array}{l}\text { Goepfert, } 2013 \\
\text { [36] Europe }\end{array}$ & Elective cardiac & High & $100(50 / 50)$ & $\begin{array}{l}\text { Intra, } \\
\text { post }\end{array}$ & $S W<10 \%$ & $\begin{array}{l}\mathrm{Cl}>2.0 \mathrm{l} / \mathrm{min} / \mathrm{m}^{2}, \mathrm{MAP}>65 \mathrm{mmHg} \\
\text { HR } 50-100 \mathrm{bpm}, \text { EVLWI } \leq 12 \mathrm{ml} / \mathrm{kg}\end{array}$ & Fluids, inotropes & $\mathrm{N}$ & $C V$, infectious, respiratory, renal \\
\hline $\begin{array}{l}\text { Harten, } 2008 \\
\text { [35] Europe }\end{array}$ & $\begin{array}{l}\text { Emergency } \\
\text { abdominal }\end{array}$ & High & $29(15 / 14)$ & Intra & PPV $<10 \%$ & N/A & Fluids & Y & $\begin{array}{l}\text { CV, Gl, infectious, renal, } \\
\text { respiratory }\end{array}$ \\
\hline $\begin{array}{l}\text { Kapoor, } 2008 \\
\text { [39] India }\end{array}$ & Cardiac & High & $27(14 / 13)$ & $\begin{array}{l}\text { Intra, } \\
\text { post }\end{array}$ & $S W<10 \%$ & $\begin{array}{l}\mathrm{Cl}>2.5 \mathrm{~mL} / \mathrm{min} / \mathrm{m}^{2}, \mathrm{CVP}>6 \mathrm{mmHg} \\
\mathrm{ScVO} \mathrm{O}_{2}>70 \%, \mathrm{SVI}>30 \mathrm{ml} / \mathrm{m}^{2} \\
\mathrm{SVRI}>1,500 \mathrm{dynes} . \mathrm{s} / \mathrm{cm}^{5} / \mathrm{m}^{2} \\
\mathrm{DO}_{2} \mathrm{I}>450 \mathrm{ml} / \mathrm{min} / \mathrm{m}^{2}\end{array}$ & Fluids, inotropes & Y & $\mathrm{Gl}, \mathrm{CV}$, renal, respiratory \\
\hline $\begin{array}{l}\text { Lopes, } 2007 \\
\text { [10] Brazil }\end{array}$ & Major abdominal & High & $33(16 / 17)$ & Intra & PPV $<10 \%$ & N/A & Fluids & Y & $\begin{array}{l}\mathrm{CV}, \mathrm{Gl} \text {, infectious, renal, } \\
\text { respiratory }\end{array}$ \\
\hline $\begin{array}{l}\text { Mayer, } 2010 \\
\text { [40] Europe }\end{array}$ & Major abdominal & High & $60(30 / 30)$ & Intra & $S W<12 \%$ & $\begin{array}{l}\mathrm{Cl}>2.5 \mathrm{~mL} / \mathrm{min} / \mathrm{m}^{2}, \mathrm{MAP}>65 \mathrm{mmHg} \\
\mathrm{SVI}>35 \mathrm{ml} / \mathrm{m}^{2}\end{array}$ & Fluids, inotropes & Y & Renal, respiratory \\
\hline $\begin{array}{l}\text { Ramsingh, } 2013 \\
\text { [34] USA }\end{array}$ & Major abdominal & High & $38(20 / 18)$ & Intra & $\mathrm{SW}<13 \%$ & N/A & Fluids & N & - \\
\hline $\begin{array}{l}\text { Salzwedel, } 2013 \\
\text { [30] Europe }\end{array}$ & Elective abdominal & Moderate & $160(81 / 79)$ & Intra & PPV $<10 \%$ & $\mathrm{Cl}>2.5 \mathrm{~mL} / \mathrm{min} / \mathrm{m}^{2}, \mathrm{MAP}>65 \mathrm{mmHg}$ & Fluids, inotropes & $\mathrm{N}$ & $\begin{array}{l}\mathrm{CV}, \mathrm{Gl} \text {, infectious, renal, } \\
\text { respiratory }\end{array}$ \\
\hline $\begin{array}{l}\text { Sheeren, } 2013 \\
\text { [33] Europe }\end{array}$ & Major abdominal & High & $52(26 / 26)$ & Intra & $S W<10 \%$ & SV increase $>10 \%$ & Fluids & Y & $\begin{array}{l}\mathrm{CV}, \mathrm{Gl} \text {, infectious, renal, } \\
\text { respiratory }\end{array}$ \\
\hline $\begin{array}{l}\text { Zhang Ju, } 2012 \\
\text { [32] China }\end{array}$ & Major abdominal & Low & $60(20 / 40)$ & Intra & PPV $<11 \%$ & N/A & Fluids & $\mathrm{N}$ & $\begin{array}{l}\text { CV, Gl, infectious, renal, } \\
\text { respiratory }\end{array}$ \\
\hline $\begin{array}{l}\text { Zhang Ji, } 2013 \\
\text { [31] China }\end{array}$ & Thoracic & Moderate & $60(30 / 30)$ & Intra & $\mathrm{SW}<9 \%$ & $\mathrm{Cl}>2.5 \mathrm{~mL} / \mathrm{min} / \mathrm{m}^{2}, \mathrm{MAP}>65 \mathrm{mmHg}$ & Fluids, inotropes & $\mathrm{N}$ & Gl, infectious, renal, Respiratory \\
\hline $\begin{array}{l}\text { Zheng, } 2013 \\
\text { [29] China }\end{array}$ & Elective abdominal & Moderate & $60(30 / 30)$ & $\begin{array}{l}\text { Intra, } \\
\text { post }\end{array}$ & $S W<12 \%$ & $\begin{array}{l}\mathrm{Cl}>2.5 \mathrm{~mL} / \mathrm{min} / \mathrm{m}^{2}, \mathrm{MAP}>65 \mathrm{mmHg}, \\
\mathrm{SVI}>35 \mathrm{ml} / \mathrm{m}^{2}\end{array}$ & Fluids, inotropes & $\mathrm{N}$ & $\mathrm{CV}, \mathrm{Gl}$ \\
\hline
\end{tabular}

"Number of participants displayed as overall (control/intervention); complications. GDFTdyn: goal-directed fluid therapy based on dynamic parameters; SVV: stroke volume variation; CV: cardiovascular; GI: abdominal (gastrointestinal/liver); MAP: mean arterial pressure; CVP: central venous pressure; SPV: systolic pressure variation; N/A, not available; PVI: pleth variability index; Cl: cardiac index; HR, heart rate; EVLWI: extravascular lung water index; PPV: pulse pressure variation; SVI: stroke volume index; SVRI: systemic vascular resistance index; $\mathrm{ScvO}_{2}$ : central venous oxygen saturation; $\mathrm{DO}_{2}$ l: oxygen delivery index. 
Table 2 Risk of bias assessed using the SIGN score

\begin{tabular}{lll}
\hline Study & SIGN score & SIGN comment \\
\hline Benes, 2010 [38] Europe & ++ & - \\
Buettner, 2008 [11] Europe & - & Blinding and concealment not clear \\
Forget, 2010 [37] Europe & ++ & - \\
Goepfert, 2013 [36] Europe & ++ & - \\
Harten, 2008 [35] Europe & - & Blinding not clear, outcomes not defined \\
Kapoor, 2008 [39] India & - & Randomization and blinding not clear, outcomes not defined \\
Lopes, 2007 [10] Brazil & ++ & - \\
Mayer, 2010 [40] Europe & + & Randomization not clear \\
Ramsingh, 2013 [34] USA & + & Intention-to-treat analysis not performed. \\
Salzwedel, 2013 [30] Europe & ++ & Multicentric trial \\
Sheeren, 2013 [33] Europe & + & Intention-to-treat analysis not performed, multicentric trial \\
Zhang Ju, 2012 [32] China & + & Intention-to-treat analysis not performed \\
Zhang Ji, 2013 [31] China & - & Randomization and blinding not clear, outcomes not defined \\
Zheng, 2013 [29] China & ++ & - \\
\hline
\end{tabular}

SIGN: The Scottish Intercollegiate Guidelines Network.

fluid are equivalent [42]. Therefore, one can expect similar benefits when using dynamic parameters than when using flow parameters to guide fluid therapy. This is what our meta-analysis does confirm: clinical benefits of GDFTdyn are comparable to those reported with GDFT based on flow parameters $[46,51]$.

Fuelled by the growing number of clinical studies and meta-analyses demonstrating the value of GDFT, official recommendations have been published [52]. However, despite these recommendations, adoption of GDFT remains poor [53]. A recent survey showed that a minority of anaesthetists use GDFT in patients undergoing highrisk surgery, whereas they believe they should [9].

For GDFT, the use of dynamic parameters has several potential advantages over the use of flow parameters. First, it has the advantage of being simple, whereas the use of flow parameters requires interventions and calculations.
For instance, the stroke volume fluid optimization strategy, currently recommended both in the UK and in France $[54,55]$, requires the assessment and quantification of the percentage change in stroke volume during a standardized fluid challenge. Oxygen delivery optimization strategies require intermittent calculations of the oxygen delivery index based on the simultaneous measurement of cardiac output, hemoglobin and arterial oxygen saturation by different devices. As a result, fluid strategies based on flow parameters are often perceived as complex and timeconsuming by caregivers. In contrast, using dynamic parameters does not require any intervention to know if the patient is a fluid responder or not (a high SPV, PPV, SVV or PVI value suggests that the patient is fluid responsive), nor any calculations (delta change in stroke volume, oxygen delivery). Caregivers simply have to monitor dynamic parameters and ensure the value remains below a

\begin{tabular}{|c|c|c|c|c|c|c|c|c|c|}
\hline Study or Subgroup & \multicolumn{2}{|c|}{ Experimental } & \multicolumn{2}{|c|}{ Control } & Weight & $\begin{array}{c}\text { Odds Ratio } \\
\text { M-H, Random, } 95 \% \mathrm{Cl}\end{array}$ & \multicolumn{3}{|c|}{$\begin{array}{c}\text { Odds Ratio } \\
\text { M-H, Random, 95\% Cl }\end{array}$} \\
\hline Benes $2010(30)$ & 18 & 60 & 35 & 60 & $16.0 \%$ & $0.31[0.14,0.65]$ & & $\longrightarrow$ & \\
\hline Forget 2010 (29) & 23 & 41 & 25 & 41 & $13.2 \%$ & $0.82[0.34,1.97]$ & & & I- \\
\hline Goepfert 2013 (28) & 34 & 50 & 42 & 50 & $11.7 \%$ & $0.40[0.15,1.06]$ & & & \\
\hline Harten 2008 (27) & 7 & 14 & 4 & 15 & $5.6 \%$ & $2.75[0.58,12.98]$ & & & \\
\hline Kapoor 2008 (31) & 1 & 13 & 2 & 14 & $2.3 \%$ & $0.50[0.04,6.28]$ & & & \\
\hline Lopes 2007 (10) & 7 & 17 & 12 & 16 & $6.0 \%$ & $0.23[0.05,1.03]$ & & & \\
\hline Mayer 2010 (32) & 6 & 30 & 15 & 30 & $9.1 \%$ & $0.25[0.08,0.79]$ & & & \\
\hline Salzwedel 2013 (22) & 21 & 79 & 36 & 81 & $18.3 \%$ & $0.45[0.23,0.88]$ & & - & \\
\hline Scheeren 2013 (25) & 12 & 26 & 16 & 26 & $9.6 \%$ & $0.54[0.18,1.62]$ & & & \\
\hline Zhang Ju 2012 (24) & 12 & 40 & 5 & 20 & $8.3 \%$ & $1.29[0.38,4.34]$ & & & \\
\hline Total $(95 \% \mathrm{Cl})$ & & 370 & & 353 & $100.0 \%$ & $0.51[0.34,0.75]$ & & & \\
\hline Total events & 141 & & 192 & & & & & & \\
\hline \multicolumn{7}{|c|}{$\begin{array}{l}\text { Heterogeneity: } \operatorname{Tau}^{2}=0.11 ; \mathrm{Chi}^{2}=12.47, \mathrm{df}=9(\mathrm{P}=0.19) ; I^{2}=28 \% \\
\text { Test for overall effect: } \mathrm{Z}=3.35(\mathrm{P}=0.0008)\end{array}$} & $\begin{array}{l}0.02 \\
\text { Favours }\end{array}$ & $\begin{array}{cc}0.1 & 1 \\
\text { experimental }\end{array}$ & 1 Favours control \\
\hline
\end{tabular}




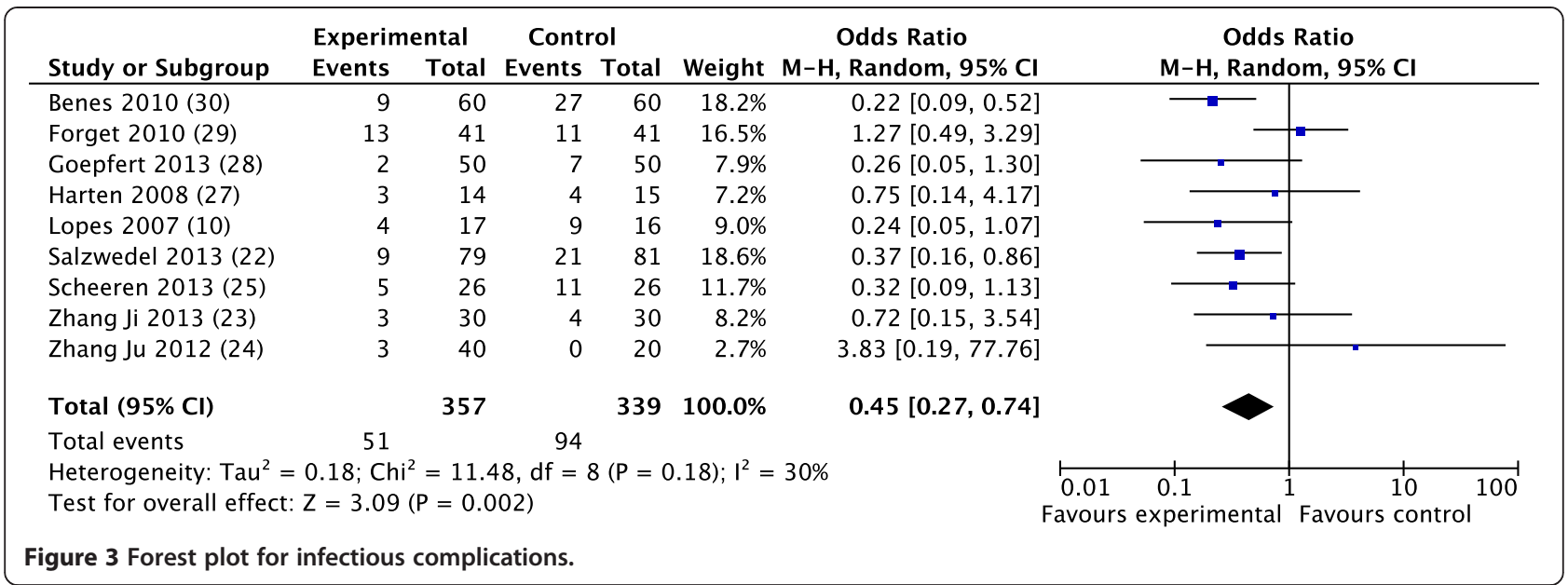

predefined target value (usually around 10 to $12 \%$ ). Simplicity may be a key element to expand the clinical adoption of GDFT. Second, using dynamic parameters may be considered as a cost-saving approach. Indeed, although SVV measurement requires the use of a cardiac output monitor, the estimation of PPV is possible from any bedside monitor displaying an arterial pressure curve. Of note, the mere eyeballing of the respiratory swings in arterial pressure may be misleading such that a real quantification of this phenomenon is required [2]. A minority of monitors currently in use in operating rooms have the ability to automatically calculate PPV. Freezing the arterial pressure tracing, and measuring systolic and diastolic pressures beat by beat to identify the maximum and minimum pulse pressure values over a single respiratory cycle is a real but time-consuming alternative to the automatic calculation of PPV.

The use of dynamic parameters has also disadvantages. The main disadvantage is the fact that they cannot be used in many patients because of limitations, which have been described in detail elsewhere [2], and do include small tidal volume $(<8 \mathrm{ml} / \mathrm{kg})$, open chest, sustained cardiac arrhythmia and abdominal hypertension (for example laparoscopy) [56]. A study [57] looking at more than 12,000 non-cardiac surgical patients concluded that, given their limitations, dynamic parameters could have been used to guide fluid therapy in only $39 \%$ of the cases, the most frequent limitation being the use of a small tidal volume for mechanical ventilation (one-third of the cases in this specific study). To decrease the risk of ventilationinduced lung injury, clinicians have lowered tidal volumes, not only in patients with respiratory failure, but also in patients with healthy lungs undergoing surgery. A recent study by Futier et al. [58] shows that using tidal volumes of 6 to $8 \mathrm{ml} / \mathrm{kg}$ during abdominal surgery is associated with a better post-operative outcome than when using a tidal volume of 10 to $12 \mathrm{ml} / \mathrm{kg}$. If such low tidal volumes ( 6 to $8 \mathrm{ml} / \mathrm{kg}$ ) were to be adopted widely to ventilate

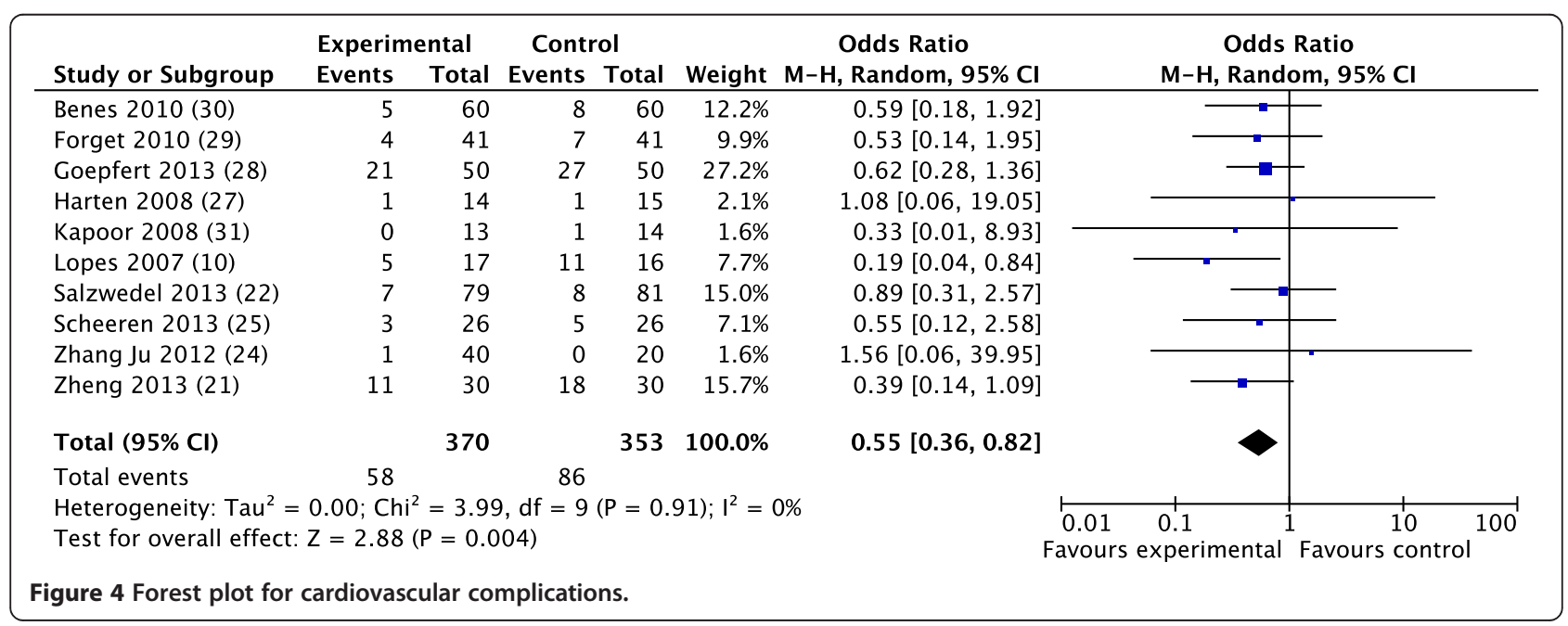




\begin{tabular}{|c|c|c|c|c|c|c|c|c|}
\hline Study or Subgroup & $\begin{array}{l}\text { Experim } \\
\text { Events }\end{array}$ & $\begin{array}{l}\text { ental } \\
\text { Total }\end{array}$ & \multicolumn{2}{|c|}{ Control } & Weight & $\begin{array}{c}\text { Odds Ratio } \\
\text { M-H, Random, } 95 \% \mathrm{Cl}\end{array}$ & \multicolumn{2}{|c|}{$\begin{array}{c}\text { Odds Ratio } \\
\mathrm{M}-\mathrm{H}, \text { Random, } 95 \% \mathrm{Cl}\end{array}$} \\
\hline Benes $2010(30)$ & 1 & 60 & 2 & 60 & $3.1 \%$ & $0.49[0.04,5.57]$ & & \\
\hline Forget 2010 (29) & 8 & 41 & 11 & 41 & $16.2 \%$ & $0.66[0.23,1.86]$ & 7 & - \\
\hline Harten 2008 (27) & 4 & 14 & 1 & 15 & $3.3 \%$ & $5.60[0.54,57.95]$ & & \\
\hline Kapoor 2008 (31) & 0 & 13 & 0 & 14 & & Not estimable & & \\
\hline Lopes 2007 (10) & 1 & 17 & 4 & 16 & $3.4 \%$ & $0.19[0.02,1.90]$ & & - \\
\hline Salzwedel 2013 (22) & 16 & 79 & 22 & 81 & $31.0 \%$ & $0.68[0.33,1.42]$ & $\rightarrow$ & - \\
\hline Scheeren 2013 (25) & 2 & 26 & 2 & 26 & $4.3 \%$ & $1.00[0.13,7.69]$ & & \\
\hline Zhang Ji 2013 (23) & 6 & 30 & 12 & 30 & $13.2 \%$ & $0.38[0.12,1.19]$ & - & \\
\hline Zhang Ju 2012 (24) & 8 & 40 & 5 & 20 & $10.9 \%$ & $0.75[0.21,2.68]$ & & \\
\hline Zheng 2013 (21) & 8 & 30 & 18 & 30 & $14.7 \%$ & $0.24[0.08,0.72]$ & & \\
\hline Total $(95 \% \mathrm{Cl})$ & & 350 & & 333 & $100.0 \%$ & $0.56[0.37,0.86]$ & & \\
\hline Total events & 54 & & 77 & & & & & \\
\hline $\begin{array}{l}\text { Heterogeneity: } \mathrm{Tau}^{2}= \\
\text { Test for overall effect }\end{array}$ & $\begin{array}{l}0.01 ; \mathrm{Chi} \\
\mathrm{Z}=2.65\end{array}$ & $\begin{array}{l}{ }^{2}=8.22 \\
(P=0.0\end{array}$ & 2. $\mathrm{df}=8$ & $(P=0.4$ & $41) ; 1^{2}=3$ & & $\begin{array}{ccc}0.01 & 0.1 & 1 \\
\text { Favours experimental }\end{array}$ & \begin{tabular}{|c|c|}
10 & 100 \\
Favours control & 100
\end{tabular} \\
\hline
\end{tabular}

patients in operating theatres, this would significantly decrease the applicability of dynamic parameters for GDFT. However, this study [58] does not disqualify the use of intermediate tidal volumes ( 8 to $10 \mathrm{ml} / \mathrm{kg}$ ) that would be compatible with the use of dynamic parameters for GDFT.

The main limitation of our study is the heterogeneity of the randomized controlled trials we analyzed. First, we observed a statistical (the $\mathrm{Q}$ and $\mathrm{I}^{2}$ tests) heterogeneity and inconsistency among studies investigating the effects of GDFTdyn on ICU and hospital length of stay, as well as on renal function. Previous meta-analyses have shown a significant reduction in renal insufficiency with GDFT [43]. A benefit has also been reported for hospital length of stay, with a reduction ranging between one and two days $[51,59]$. In contrast, previous meta-analyses failed to demonstrate a decrease in ICU length of stay. Therefore, the effect or lack of effect of GDFTdyn on ICU and hospital length of stay, as well as on renal function, deserves further investigation before drawing any definitive conclusion. Beside the heterogeneity detected by statistical tests, one must acknowledge that the randomized controlled trials were also different with regard to the definition of post-surgical complications. Unfortunately, there is no universal definition for post-surgical complications such as bacterial pneumonia (protected or non-protected bacteriological samples) or acute renal insufficiency (oliguria or increase in creatinine level), and this certainly contributes to the heterogeneity of the studies we analyzed. If fluid management was always based on the monitoring of dynamic parameters, different trigger values, ranging from 9 to $13 \%$ (Table 1), were used to give fluid. In addition, some hemodynamic protocols included additional static parameters such as blood pressure and cardiac output (Table 1). The heterogeneity among treatment protocols and definition of complications is a common feature of previous GDFT meta-analyses [43-50], but it is important to bear in mind that it may have influenced our findings.

\section{Conclusion}

Our meta-analysis suggests that GDFTdyn decreases postsurgical morbidity, infectious, cardiac and abdominal complications, as well as ICU length of stay. Pending limitations to their use being understood and respected, dynamic parameters may represent an alternative to flow

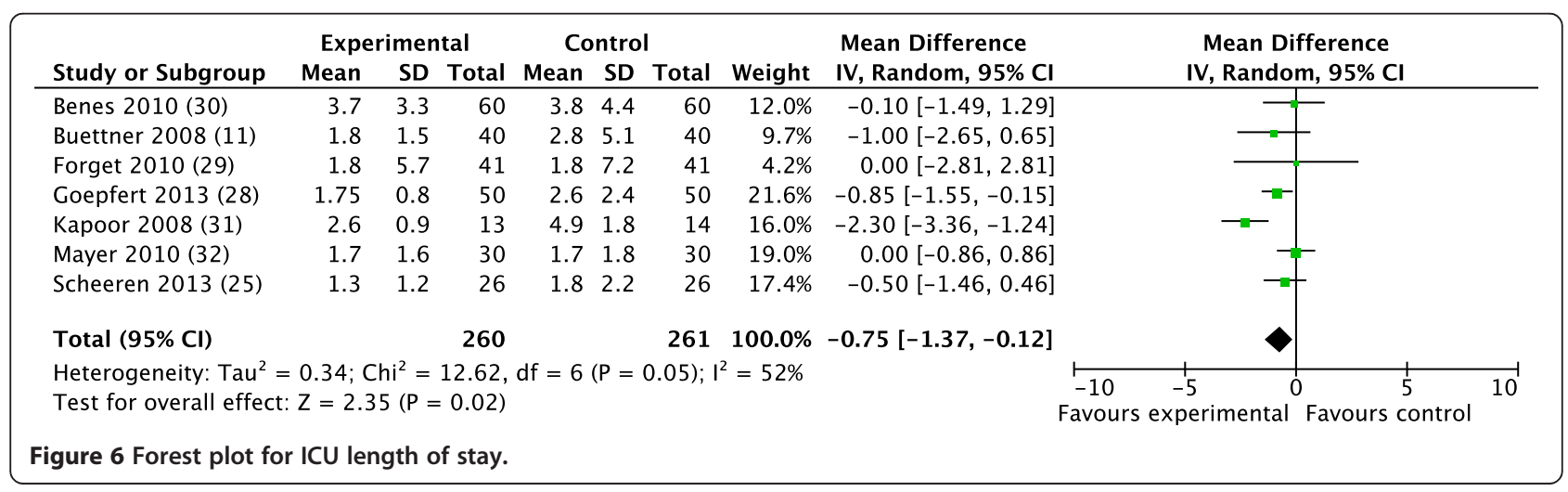


parameters to guide peri-operative fluid therapy. Because of the heterogeneity of studies analyzed, large prospective clinical trials would be useful to confirm our findings.

\section{Key messages}

- We analyzed 14 randomized controlled trials investigating the value of goal-directed fluid therapy (GDFT) based on dynamic parameters (GDFTdyn) to improve post-surgical outcome.

- Our meta-analysis showed that GDFTdyn is associated with a significant decrease in post-surgical morbidity, defined as the proportion of patients developing one or more complication.

- This decrease in post-surgical morbidity was related to a significant reduction in infectious, cardiovascular, and abdominal complications and was associated with decrease in ICU length of stay.

- GDFTdyn may be an interesting alternative to classical GDFT strategies, which are based on flow parameters such as cardiac output or oxygen delivery.

\section{Additional files}

\section{Additional file 1: PRISMA checklist.}

Additional file 2: Search strategies.

\section{Abbreviations}

Cl: confidence interval; GDFT: goal-directed fluid therapy; GDFTdyn: goal-directed fluid therapy based on dynamic parameters; OR: odds ratio; PPV: pulse pressure variation; PVI: pleth variability index; RCTs: randomized controlled trials; SIGN: The Scottish Intercollegiate Guidelines Network; SPV: systolic pressure variation; SW: stroke volume variation; WMD: weight mean difference.

\section{Competing interests}

$J B$ received honoraria from Edwards Lifesciences. MG and NB have no conflict of interest to declare. FM is a vice president, Global Medical Strategy, at Edwards Lifesciences. This meta-analysis does not recommend the use of any specific dynamic parameters, or the use of any specific product.

\section{Authors' contributions \\ $\mathrm{JB}$ and FM contributed to the design of the work; the acquisition and interpretation of data for the work; drafting the work and revising it critically for important intellectual content; and final approval of the version to be published. MG and NB contributed to the acquisition of data for the work; analysis and interpretation of data for the work; revising the work critically for important intellectual content; and final approval of the version to be published. All authors have read and approved the final manuscript.}

\section{Acknowledgements}

The authors wish to express their sincere gratitude to Drs. P. Forget (Brussels, Belgium), M. Goepfert (Hamburg, Germany), J. Harten (Glasgow, UK), P. Malhotra Kapoor (New Delhi, India), D. Ramsingh (Orange, CA, USA), D. Reuter (Hamburg, Germany), T. Scheeren (Groningen, The Netherlands), S. Sakka (Koeln, Germany), Jun Zhang (Shanghai, China) for having supplied unpublished personal data. We also thank the department of Anaesthesia and Intensive Care Medicine, The Faculty of Medicine and University hospital in Plzen, Charles University Prague with the support of the Charles University Research Fund 'PRVOUK' (project number P36).

\section{Author details}

'Department of Anaesthesia and Intensive Care Medicine, The Faculty of Medicine and University hospital in Plzen, Charles University Prague, Alej Svobody 80, 30640 Plzen, Czech Republic. Department of Emergency and Organ Transplantation, Anaesthesia and Intensive Care Unit, University of Bari, Policlinico, Piazza G. Cesare 11, 70124 Bari, Italy. ${ }^{3}$ Critical Care, Edwards Lifesciences, 1 Edwards Way, Irvine, CA, USA.

Received: 3 March 2014 Accepted: 9 October 2014

Published online: 28 October 2014

\section{References}

1. Massumi RA, Mason DT, Vera Z, Zelis R, Otero J, Amsterdam EA: Reversed pulsus paradoxus. N Engl J Med 1973, 289:1272-1275.

2. Michard F: Changes in arterial pressure during mechanical ventilation Anesthesiology 2005, 103:419-428. quiz 449-500.

3. Michard F, Boussat S, Chemla D, Anguel N, Mercat A, Lecarpentier Y, Richard C, Pinsky MR, Teboul JL: Relation between respiratory changes in arterial pulse pressure and fluid responsiveness in septic patients with acute circulatory failure. Am J Respir Crit Care Med 2000, 162:134-138.

4. Perel A: Assessing fluid responsiveness by the systolic pressure variation in mechanically ventilated patients. Systolic pressure variation as a guide to fluid therapy in patients with sepsis-induced hypotension. Anesthesiology 1998, 89:1309-1310.

5. Tavernier B, Makhotine O, Lebuffe G, Dupont J, Scherpereel P: Systolic pressure variation as a guide to fluid therapy in patients with sepsis-induced hypotension. Anesthesiology 1998, 89:1313-1321.

6. Berkenstadt H, Margalit N, Hadani M, Friedman Z, Segal E, Villa Y, Perel A Stroke volume variation as a predictor of fluid responsiveness in patients undergoing brain surgery. Anesth Analg 2001, 92:984-989.

7. Cannesson M, Desebbe O, Rosamel P, Delannoy B, Robin J, Bastien O, Lehot JJ: Pleth variability index to monitor the respiratory variations in the pulse oximeter plethysmographic waveform amplitude and predict fluid responsiveness in the operating theatre. $\mathrm{Br} J$ Anaesth 2008, 101:200-206.

8. Boldt J, Lenz M, Kumle B, Papsdorf M: Volume replacement strategies on intensive care units: results from a postal survey. Intensive Care Med 1998, 24:147-151

9. Srinivasa S, Kahokehr A, Soop M, Taylor M, Hill AG: Goal-directed fluid therapy- a survey of anaesthetists in the UK, USA, Australia and New Zealand. BMC Anesthesio/ 2013, 13:5.

10. Lopes MR, Oliveira MA, Pereira V, Lemos I, Auler J, Michard F: Goal-directed fluid management based on pulse pressure variation monitoring during high-risk surgery: a pilot randomized controlled trial. Crit Care 2007, 11:R100.

11. Buettner M, Schummer W, Huettemann E, Schenke S, van Hout N, Sakka SG: Influence of systolic-pressure-variation-guided intraoperative fluid management on organ function and oxygen transport. $\mathrm{Br} J$ Anaesth 2008, 101:194-199.

12. Moher D, Liberati A, Tetzlaff J, Altman DG, PRISMA Group: Preferred reporting items for systematic reviews and meta-analyses: the PRISMA statement. BMJ 2009, 339:b2535.

13. Chapter 6: Searching for studies. In: Higgins JPT, Green S (editors). Cochrane Handbook for Systematic Reviews of Interventions Version 5.1.0 [updated March 2011]. [http://www.cochrane-handbook.org]

14. Scottish Intercollegiate Guidelines Network (SIGN) 50: A guideline developer's handbook. [http://www.sign.ac.uk/guidelines/fulltext/50/ index.html]

15. Jadad AR, Moore RA, Carroll D, Jenkinson C, Reynolds DJ, Gavaghan DJ, McQuay HJ: Assessing the quality of reports of randomized clinical trials: is blinding necessary? Control Clin Trials 1996, 17:1-12.

16. Jüni $P$, Witschi $A$, Bloch $R$, Egger $M$ : The hazards of scoring the quality of clinical trials for meta-analysis. JAMA 1999, 282:1054-1060

17. Chapter 8: Assessing risk of bias in included studies. In: Higgins JPT Green S (editors). Cochrane Handbook for Systematic Reviews of Interventions Version 5.1.0 [updated March 2011]. [http://www.cochranehandbook.org]

18. Higgins JPT, Thompson SG: Quantifying heterogeneity in a meta-analysis. Stat Med 2002, 21:1539-1558.

19. Higgins JPT, Thompson SG, Deeks JJ, Altman DG: Measuring inconsistency in meta-analyses. BMJ 2003, 327:557-560. 
20. Chapter 9: Analysing data undertaking meta-analyses. In: Higgins JPT, Green S (editors). Cochrane Handbook for Systematic Reviews of Interventions Version 5.1.0 [updated March 2011]. [http://www.cochranehandbook.org]

21. Futier E, Constantin JM, Petit A, Chanques G, Kwiatkowski F, Flamein R, Slim $\mathrm{K}$, Sapin V, Jaber S, Bazin JE: Conservative vs restrictive individualized goal-directed fluid replacement strategy in major abdominal surgery: a prospective randomized trial. Arch Surg 2010, 145:1193-1200.

22. Lee JY, Park HY, Jung WS, Jo YY, Kwak HJ: Comparative study of pressure- and volume-controlled ventilation on stroke volume variation as a predictor of fluid responsiveness in patients undergoing major abdominal surgery. J Crit Care 2012, 27:531. e9-531.14.

23. Li C, Lin FQ, Fu SK, Chen GQ, Yang XH, Zhu CY, Zhang L, Li Q: Stroke volume variation for prediction of fluid responsiveness in patients undergoing gastrointestinal surgery. Int J Med Sci 2013, 10:148-155.

24. Wang P, Wang HW, Zhong TD: Effect of stroke volume variability- guided intraoperative fluid restriction on gastrointestinal functional recovery. Hepatogastroenterology 2012, 59:2457-2460.

25. Abdullah $\mathrm{MH}$, Hasanin AS, Mahmoud FM: Goal directed fluid optimization using Pleth variability index versus corrected flow time in cirrhotic patients undergoing major abdominal surgeries. Egypt J Anaesth 2012, 28:23-28.

26. Haas S, Eichhorn V, Hasbach T, Trepte C, Kutup A, Goetz AE, Reuter DA Goal-directed fluid therapy using stroke volume variation does not result in pulmonary fluid overload in thoracic surgery requiring one-lung ventilation. Crit Care Res Pract 2012, 2012:687018.

27. Oubaha D, Poelaert J: Does stroke volume variation guided fluid management improve postoperative outcome? Eur J Anaesthesio/ Supp/ 2009, 26:39.

28. Thuraisingham D, Williams W, Ramsingh D, Le K, Lee C, Canales C, Cannesson M: Goal-directed fluid optimization based on respiratory variations in the pulse oximeter plethysmographic waveform during moderate risk surgery (A847). 2012, [updated October 2012]: [http://www.asaabstracts.com/strands/asaabstracts/search.htm; jsessionid=95A82A39DAD34A51B155DAB0BB92974B]

29. Zheng H, Guo H, Ye JR, Chen L, Ma HP: Goal-directed fluid therapy in gastrointestinal surgery in older coronary heart disease patients: randomized trial. World J Surg 2013, 37:2820-2829.

30. Salzwedel C, Puig J, Carstens A, Bein B, Molnar Z, Kiss K, Hussain A, Belda J, Kirov MY, Sakka SG, Reuter DA: Perioperative goal-directed hemodynamic therapy based on radial arterial pulse pressure variation and continuous cardiac index trending reduces postoperative complications after major abdominal surgery: a multi-center, prospective, randomized study. Crit Care 2013, 17:R191

31. Zhang J, Chen CQ, Lei XZ, Feng ZY, Zhu SM: Goal-directed fluid optimization based on stroke volume variation and cardiac index during one-lung ventilation in patients undergoing thoracoscopy lobectomy operations: a pilot study. Clinics 2013, 68:1065-1070.

32. Zhang J, Qiao H, He Z, Wang Y, Che X, Liang W: Intraoperative fluid management in open gastrointestinal surgery: goal-directed versus restrictive. Clinics 2012, 67:1149-1155.

33. Scheeren TWL, Wiesenack C, Gerlach H, Marx G: Goal-directed intraoperative fluid therapy guided by stroke volume and its variation in high-risk surgical patients: a prospective randomized multicentre study. J Clin Monit Comput 2013, 27:225-233.

34. Ramsingh DS, Sanghvi C, Gamboa J, Cannesson M, Applegate RL: Outcome impact of goal directed fluid therapy during high risk abdominal surgery in low to moderate risk patients: a randomized controlled trial. J Clin Monit Comput 2013, 27:249-257.

35. Harten J, Crozier JEM, McCreath B, Hay A, McMillan DC, McArdle CS, Kinsella $\mathrm{J}$ : Effect of intraoperative fluid optimisation on renal function in patients undergoing emergency abdominal surgery: a randomised controlled pilot study (ISRCTN 11799696). Int J Surg 2008, 6:197-204.

36. Goepfert MS, Richter HP, Zu Eulenburg C, Gruetzmacher J, Rafflenbeul E, Roeher K, von Sandersleben A, Diedrichs S, Reichenspurner H, Goetz AE, Reuter DA: Individually optimized hemodynamic therapy reduces complications and length of stay in the intensive care unit: a prospective, randomized controlled trial. Anesthesiology 2013, 119:824-836.

37. Forget $P$, Lois $F$, de Kock M: Goal-directed fluid management based on the pulse oximeter-derived pleth variability index reduces lactate levels and improves fluid management. Anesth Analg 2010, 111:910-914.
38. Benes J, Chytra I, Altmann P, Hluchy M, Kasal E, Svitak R, Pradl R, Stepan M: Intraoperative fluid optimization using stroke volume variation in high risk surgical patients: results of prospective randomized study. Crit Care 2010, 14:R118.

39. Kapoor P, Kakani M, Chowdhury U, Choudhury M, Lakshmy R, Kiran U: Early goal-directed therapy in moderate to high-risk cardiac surgery patients. Ann Card Anaesth 2008, 11:27-34.

40. Mayer J, Boldt J, Mengistu A, Rohm K, Suttner S: Goal-directed intraoperative therapy based on autocalibrated arterial pressure waveform analysis reduces hospital stay in high-risk surgical patients: a randomized, controlled trial. Crit Care 2010, 14:R18.

41. Bellamy MC: Wet, dry or something else? Br J Anaesth 2006, 97:755-757

42. Michard F, Lopes MR, Auler JOC: Pulse pressure variation: beyond the fluid management of patients with shock. Crit Care 2007, 11:131.

43. Brienza N, Giglio MT, Marucci M, Fiore T: Does perioperative hemodynamic optimization protect renal function in surgical patients? A meta-analytic study. Crit Care Med 2009, 37:2079-2090.

44. Dalfino L, Giglio MT, Puntillo F, Marucci M, Brienza N: Haemodynamic goal-directed therapy and postoperative infections: earlier is better. A systematic review and meta-analysis. Crit Care 2011, 15:R154.

45. Giglio MT, Marucci M, Testini M, Brienza N: Goal-directed haemodynamic therapy and gastrointestinal complications in major surgery: a meta-analysis of randomized controlled trials. Br J Anaesth 2009, 103:637-646.

46. Hamilton MA, Cecconi M, Rhodes A: A systematic review and meta-analysis on the use of preemptive hemodynamic intervention to improve postoperative outcomes in moderate and high-risk surgical patients. Anesth Analg 2011, 112:1392-1402.

47. Arulkumaran N, Corredor C, Hamilton MA, Ball J, Grounds RM, Rhodes A, Cecconi M: Cardiac complications associated with goal-directed therapy in high-risk surgical patients: a meta-analysis. $\mathrm{Br} J$ Anaesth 2014, 112:648-659.

48. Cecconi M, Corredor C, Arulkumaran N, Abuella G, Ball J, Grounds RM, Hamilton M, Rhodes A: Clinical review: goal-directed therapy-what is the evidence in surgical patients? The effect on different risk groups. Crit Care 2013, 17:209

49. Grocott MPW, Dushianthan A, Hamilton MA, Mythen MG, Harrison D, Rowan K, Optimisation Systematic Review Steering Group: Perioperative increase in global blood flow to explicit defined goals and outcomes after surgery: a Cochrane Systematic Review. Br J Anaesth 2013, 111:535-548.

50. Pearse RM, Harrison DA, MacDonald N, Gillies MA, Blunt M, Ackland G, Grocott MPW, Ahern A, Griggs K, Scott R, Hinds C, Rowan K, OPTIMISE Study Group: Effect of a perioperative, cardiac output-guided hemodynamic therapy algorithm on outcomes following major gastrointestinal surgery: a randomized clinical trial and systematic review. JAMA 2014, 311:2181-2190.

51. Grocott MPW, Dushianthan A, Hamilton MA, Mythen MG, Harrison D, Rowan K, Optimisation Systematic Review Steering Group: Perioperative increase in global blood flow to explicit defined goals and outcomes following surgery. Cochrane Database Syst Rev 2012, 11:CD004082.

52. Powell-Tuck J, Gosling P, Lobo D, Allison S, Carlson G, Gore M, Lewington A, Pearse $R$, Mythen M: British consensus guidelines on intravenous fluid therapy for adult surgical patients (GIFTASUP). London: NHS National Library of Health; 2009. [http://www.ics.ac.uk/EasysiteWeb/getresource.axd? AssetID=466\&type=full\&servicetype=Attachment]

53. Miller TE, Roche AM, Gan TJ: Poor adoption of hemodynamic optimization during major surgery: are we practicing substandard care? Anesth Analg 2011, 112:1274-1276.

54. Intraoperative fluid management technologies adoption pack. [http://webarchive.nationalarchives.gov.uk/20130701143131/http://www.ntac. nhs.uk/nmsruntime/saveasdialog.aspx? ID $=1225 \&$ sID $=1010]$

55. Vellet B, Blanloeil Y, Cholley B, Orliaguet G, Pierre S, Tavernier B: Guidelines for perioperative hemodynamic optimization. Ann Fr Anesth Reanim 2013, 32:454-462.

56. Michard F: Stroke volume variation: from applied physiology to improved outcomes. Crit Care Med 2011, 39:402-403.

57. Maguire S, Rinehart J, Vakharia S, Cannesson M: Technical communication: respiratory variation in pulse pressure and plethysmographic waveforms: intraoperative applicability in a North American academic center. Anesth Analg 2011, 112:94-96.

58. Futier E, Constantin JM, Paugam-Burtz C, Pascal J, Eurin M, Neuschwander A, Marret E, Beaussier M, Gutton C, Lefrant JY, Allaouchiche B, Verzilli D, Leone 
M, De Jong A, Bazin JE, Pereira B, Jaber S, IMPROVE Study Group: A trial of intraoperative low-tidal-volume ventilation in abdominal surgery. $N$ Engl J Med 2013, 369:428-437.

59. Corcoran T, Rhodes JEJ, Clarke S, Myles PS, Ho KM: Perioperative fluid management strategies in major surgery: a stratified meta-analysis. Anesth Analg 2012, 114:640-651.

doi:10.1186/s13054-014-0584-z

Cite this article as: Benes et al:: The effects of goal-directed fluid therapy based on dynamic parameters on post-surgical outcome: a meta-analysis of randomized controlled trials. Critical Care 2014 18:584.

\section{Submit your next manuscript to BioMed Central and take full advantage of:}

- Convenient online submission

- Thorough peer review

- No space constraints or color figure charges

- Immediate publication on acceptance

- Inclusion in PubMed, CAS, Scopus and Google Scholar

- Research which is freely available for redistribution 